\title{
In-Person Contact Begets Calling and Texting: Interpersonal Motives for Cell Phone Use, Face-to-Face Interaction, and Loneliness
}

\author{
Borae Jin, M.A., and Namkee Park, Ph.D. ${ }^{2}$
}

\begin{abstract}
This study examined how cell-phone use is related to interpersonal motives for using cell phones, face-to-face communication, and loneliness. A survey of 232 college students who owned a cell phone revealed that affection and inclusion were relatively strong motivations for using voice calls and text messaging, and that interpersonal motives were positively related to the amount of cell-phone use, including calling and texting. The amount of face-to-face interaction was positively associated with the participants' cell-phone use and their interpersonal motives for using cell phones: the more the participants engaged in face-to-face interaction with other people, the higher their motives were and the more frequent cell-phone use was. Loneliness did not have a direct relation to cell-phone use. Instead, the participants with higher levels of loneliness were less likely to engage in face-to-face social interaction, which led them to use cell phones less and to be less motivated to use cell phones for interpersonal purposes.
\end{abstract}

\section{Introduction}

C OMMUNiCATION TECHNOLOGIES ALLOW US TO INTERACT with other people in various ways. Nowadays, using a cell phone (i.e., mobile communication) is one of the most pervasive modes of interpersonal communication among the various types of mediated communication, particularly for college stunents. ${ }^{1}$ Thanks to its mobility, the cell phone seems to serve our communication needs better than any other communication technologies. Indeed, a recent study found that cell phones gratify users' various needs (e.g., companionship, closeness, and care) more satisfactorily than other media, such as e-mails, IMs, and landline telephones. ${ }^{2}$ Given that people, as human beings, have an innate desire to relate to other people, ${ }^{3,4}$ cell phones must play a role in fulfilling our need to belong, which requires frequent social interactions. ${ }^{5}$ In this sense, Licoppe ${ }^{6}$ views carrying a cell phone as being "connected" and ready to communicate with others, and Katz and Aakhus ${ }^{7}$ claim that "perpetual contact" (i.e., the pursuit of the ideal of communication) is the motive for people's use of communication technologies.

Studies suggest that the primary purpose for using cell phones is to communicate with other people within already established interpersonal networks, and this motive is related to more frequent use of cell phones. ${ }^{8,9}$ Therefore, individuals' personal relationships would play a role in their cell-phone use. For instance, people's daily face-to-face (ftf) interaction may have effects on their cell-phone use because they tend to use cell phones with those whom they often meet in person. ${ }^{10}$ It follows, then, that individuals' characteristics relevant to how they relate to and communicate with other people, such as loneliness, would also influence their tendency to use cell phones. In addition to its critical role in people's ftf interpersonal activities, ${ }^{11,12}$ loneliness is significantly associated with how people communicate through or with communication technologies. ${ }^{13,14}$ Therefore, loneliness may be associated with mobile communication, as it is with $\mathrm{ftf}$ communication. The present study replicates and extends prior studies on cell-phone use by examining how the use of cell phones and its interpersonal motives are associated with $\mathrm{ftf}$ interpersonal communication and loneliness.

\section{Literature Review}

Why do you use cell phones?

Motives for telephone and cell-phone use. Studies on motives for using cell phones tend to rely on previous telephone research, which takes the uses and gratifications perspective. These studies attempt to explain the reasons why people make use of (cell) phones and what kinds of

\footnotetext{
A previous version of this paper was presented at the National Communication Association Annual Convention held in Chicago, IL, November 2009.

${ }^{1}$ Department of Communication Studies, University of Texas at Austin, Austin, Texas.

${ }^{2}$ Gaylord College of Journalism and Mass Communication, University of Oklahoma, Norman, Oklahoma.
} 
expectations or gratifications people would find in using (cell) phones. These telephone studies generally found two categories of motives (or gratifications): intrinsic and instrumental motives. ${ }^{15-17}$ Intrinsic or social motives refer to communicating with others through the telephone for the purpose of companionship, while instrumental or taskoriented motives refer to the use of the telephone for utility, for example, information seeking or making appointments.

On this basis, cell-phone studies have found similar yet different motives. Leung and $\mathrm{Wei}^{8}$ found that the motives for using cell phones also have social and instrumental dimensions and, further, they identified additional motives such as mobility, immediacy, and fashion and status. People are using their cell phones because cell phones provide immediate access, regardless of time and location, eliminate the need to find a landline phone, and make them look good. Wei and Lo $^{9}$ also demonstrated similar motives: information seeking, social utility, affection, fashion and status, mobility, and accessibility.

These findings indicate that there are various types of reasons why people use cell phones. Although mobility, immediacy, and fashion are unique types of motives for cellphone use, we think that these motives are more relevant to "buying" or "carrying" a cell phone than to communicating through it. That is, people buy and carry a cell phone because it enables them to contact other people immediately whenever and wherever they want to. Some studies found that these new dimensions of motives for cell-phone use, such as mobility and immediate accessibility, do not explain the variance in cell-phone use very well (e.g., frequency and time), ${ }^{8,9}$ supporting our reasoning that those motives may have less to do with using cell phones. Although the cell phone is becoming an aggregate of all kinds of new technologies, such as the Internet, music players, games, and so on, people still spend about $90 \%$ of their time making phone calls when using cell phones. ${ }^{18}$ That is, people use their cell phones mainly to communicate with other people. Therefore, the present study focuses on the interpersonal communication motives for using cell phones.

Interpersonal motives for cell-phone use. As Maslow ${ }^{3}$ stated, belonging is one of the fundamental human needs, and every person needs to have social relations. Baumeister and Leary ${ }^{5}$ defined the need to belong as a desire to form interpersonal attachments, and argued that it is a fundamental motive with important consequences for social functioning. This basic desire may lead people to enact communicative behavior that makes it possible to initiate and maintain relationships. As such, if people need to interact with other people, what are they specifically obtaining by communicating with others? According to Schutz, ${ }^{4}$ there are three basic needs when people communicate with others: inclusion, control, and affection. Inclusion is the need to acknowledge each other and interact satisfactorily; control is the need to initiate or preserve power and influence over others; and affection is the need to achieve or maintain relationships based on love, mutual support, and devotion. ${ }^{4}$ In short, people communicate with others to feel included, important, and cared about.

In addition to these three motives, Rubin et al. ${ }^{19}$ identified three other interpersonal communication motives: pleasure, escape, and relaxation. Pleasure represents the pursuit of entertainment and excitement through interpersonal communication; escape involves avoiding other activities by engaging in interpersonal communication; and relaxation describes the need to rest and unwind through communication. These three motives are the ones derived from earlier mass communication research, while inclusion, control, and affection are more interpersonally oriented motives. ${ }^{19} \mathrm{Al}-$ though these six interpersonal motives are more pertinent to social motives, the control motive (e.g., "to get something I don't have," "to tell others what to do") seems to involve an instrumental aspect of interpersonal communication. Thus interpersonal motives cover the social and instrumental motives, at least partly, that previous telephone studies found.

The current study examines how well the use of cell phones satisfies these six interpersonal motives. We also hypothesize that the stronger the motives, the greater the use of cell phones. Because the cell phone has two major interpersonal channels-calling and texting-research questions and hypotheses are raised separately for each channel:

RQ1: To what extent do people have each of the six interpersonal motives for calling through cell phones?

RQ2: To what extent do people have each of the six interpersonal motives for texting through cell phones?

H1a: Higher levels of interpersonal motives for calling predict an increased use of voice calls.

H1b: Higher levels of interpersonal motives for texting predict an increased use of text messaging.

\section{Cell-phone use as interpersonal communication}

Face-to-face communication and cell-phone use. Using cell phones, including calling and texting, is now an important part of our daily social interaction. Accordingly, communication partners through cell phones are likely to overlap those with whom people usually interact in person. Indeed, cell-phone use tends to occur within close relationships such as families, romantic couples, and friends, ${ }^{10,20,21}$ and mobile communication is likely to strengthen established social relationships rather than extend them. ${ }^{10,22}$ People maintain family bonds, facilitate friendships, and build mutual support through cell-phone communication. ${ }^{9,10,23}$ Drawing on these findings, $\mathrm{Jin}^{24}$ claimed that people who enjoy ftf interpersonal interaction would also enjoy mobile communication, and found that people who spend more time interacting with other people in person tend to spend more time using cell phones, particularly voice calls. The present study replicates this finding:

\section{H2: A greater amount of face-to-face interaction predicts a greater amount of cell-phone use, including (a) calling and (b) texting.}

If people use their cell phones as a result of their in-person social relationships, the interpersonal motives for using cell phones should be related to $\mathrm{ftf}$ interaction as well. In other words, ftf social interaction would motivate people to engage in communication through cell phones to some degree. In parallel with this view, Wei and Lo 9 found that shyness was negatively associated with cell-phone-use motives-social 
utility and affection, in particular-and with the amount of cell-phone use. Similarly, Reid and Reid ${ }^{25}$ found social anxiety was negatively related to cell-phone use. These findings indicate that people who do not feel comfortable with $\mathrm{ftf}$ social interaction are less likely to use cell phones and also less likely to seek to satisfy their interpersonal needs by using cell phones. Considering that shyness and social anxiety are commonly associated with less involvement in social interaction, ${ }^{26}$ and if the positive relationship between $\mathrm{ftf}$ interaction and cellphone use is the case as $\mathrm{H} 2$ posited, the extent to which people interact with others in person should be positively associated with the degree to which they are motivated to use cell phones for interpersonal purposes.

H3: A greater amount of face-to-face interaction predicts higher levels of motives for cell-phone use, including (a) calling and (b) texting.

Loneliness as an antecedent. Loneliness is one of the most frequently used indexes for assessing individuals' psychosocial well-being. ${ }^{27,28}$ Scholars define loneliness as perceived deficiencies in one's ongoing relationships. ${ }^{29,30}$ Such deficiencies occur when "a person's network of relationships is either smaller or less satisfying than the person desires" (p. 55). ${ }^{29}$ Studies have consistently found a significant relationship between loneliness and some deficits in social interaction. ${ }^{28,31}$ For example, during conversations, lonely people tend to talk less, ${ }^{11}$ show lower levels of attention and involvement, and inappropriately high or low levels of selfdisclosure. ${ }^{12}$ Further, lonely people tend to be shy ${ }^{32}$ and relationally incompetent, ${ }^{31}$ and thus spend more time being alone, do fewer social activities, and have fewer close friends. ${ }^{33}$ That is, people who are involved in in-person social contact more frequently are less likely to feel lonely.

With respect to mobile communication, loneliness is associated with less frequent use of cell phones ${ }^{24}$ and lower levels of interpersonal motivations for using cell phones. ${ }^{9}$ Wei and $\mathrm{Lo}^{9}$ regarded lonely people as those who are less able to make connections with others, and assumed that these characteristics would be revealed even in mobile communication. As such, loneliness may be a constant tendency to behave and feel in certain ways. ${ }^{34}$ In line with this, we view loneliness as a stable characteristic of an individual, associated with various communicative outcomes. Thus we expect that lonelier people would communicate through cell phones less compared with less lonely people, because loneliness is associated with less involvement in $\mathrm{ftf}$ interpersonal communication, ${ }^{33}$ and because $\mathrm{ftf}$ communication is positively associated with cellphone use. ${ }^{24}$ Also, the lonely would be less inclined to use cell phones for interpersonal purposes. ${ }^{9}$

H4: Higher levels of loneliness predict smaller amounts of cell-phone use, including (a) calling and (b) texting.

H5: Higher levels of loneliness predict lower levels of interpersonal motives for cell-phone use, including (a) calling and (b) texting.

To summarize, because lonely people are less likely to communicate with other people in person, they may not use cell phones very often. Also, loneliness and $\mathrm{ftf}$ interaction would influence people's interpersonal motivations for cellphone use, and these motives affect the amount of cell-phone use. Following this reasoning, a path model is presented in which loneliness is correlated with the amount of ftf interaction, which in turn determines the extent of interpersonal motives for using cell phones and the amount of cell-phone use. This model also implies that interpersonal motives can mediate the effects of loneliness and $\mathrm{ftf}$ interaction on cellphone use. Figure 1 presents the proposed path model.

\section{Method}

\section{Participants}

Students in communication classes at two large southwestern universities, 208 from one and 93 from the other, participated in an online survey in return for extra course credit. Those who did not complete the survey and one person who reported not having a cell phone were excluded, resulting in a final sample size of 232. Of this sample, 171 $(73.7 \%)$ were female, $59(25.4 \%)$ were male, and two did not report their sex. The mean age was $20.39(S D=2.33$, ranging from 17 to 35 ), and $64.7 \%$ were Caucasian, $20.7 \%$ were Asian, and $9.5 \%$ were Hispanic.

\section{Measures}

Cell-phone use. The online survey asked participants to estimate the frequency in a day of making and receiving voice calls respectively, as well as text messages. Because the frequencies of making and receiving calls were highly correlated with each other $(r=0.82)$, they were summed to

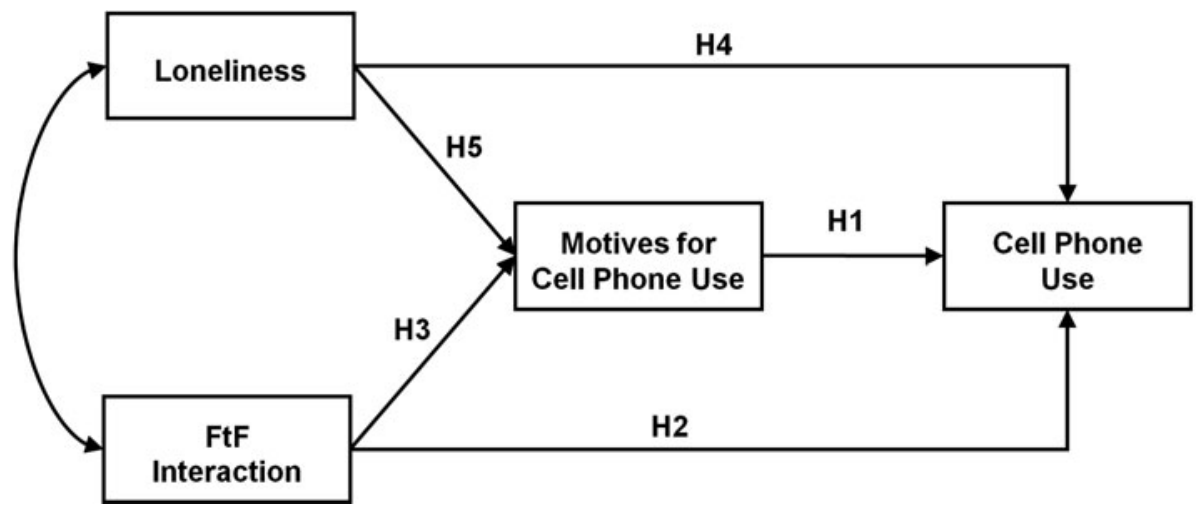

FIG. 1. Proposed path model. 
create the composite variable of calling frequency. Likewise, sending and receiving text messages were highly correlated $(r=0.98)$, and thus the same procedure was applied to compute the composite variable of texting frequency.

The average frequency with which participants used voice calls was about 13 times $(M=13.12, S D=10.80$, mode $=10$, median $=10)$ and text messaging was about 82 times $(M=82.47, S D=125.39$, mode $=100$, median $=50)$ in a day. As the large standard deviation value for each variable indicates, the distributions of these two variables were skewed in a positive direction. Thus log transformations were performed on these variables, which resulted in significant improvement in the normality of the data. These transformed variables were used in the following analyses.

Interpersonal motives for cell-phone use. The Interpersonal Communication Motives (ICM) scale ${ }^{19}$ was used to assess interpersonal motives for using voice calls and text messaging. The instructions for this scale were slightly modified for calling: participants were asked to rate how well each item represents their own reasons for talking to others using cell phones on a 7-point Likert-type scale ranging from 1 ("not at all") to 7 ("exactly"). This scale includes 28 items to measure motives of inclusion (e.g., "because I need someone to talk to or be with"), control (e.g., "because I want someone to do something for me"), affection (e.g., "to let others know I care about their feelings"), pleasure (e.g., "because it's fun"), relaxation (e.g., "because it makes me feel less tense"), and escape (e.g., "to put off something I should be doing"). The same set of items with different instructions (reasons for texting with others using cell phones) was used to assess interpersonal motives for texting. The 12 subscales, generated by a combination of the six motive categories and two channel contexts, had acceptable reliabilities, with Cronbach's alphas ranging from 0.75 to 0.94 .

Ftf interaction. Participants' $\mathrm{ftf}$ interpersonal communication was measured by three questions about the amount of time they spent in a week with their family $(M=7.59 \mathrm{~h}$ $S D=15.61$, mode $=0$, median $=1)$, friends $(M=31.10 \mathrm{~h}$, $S D=30.74$, mode $=0$, median $=20)$, and colleagues $(M=$ $11.54 \mathrm{~h}, S D=19.00$, mode $=0$, median $=5$ ) respectively These three items were reliable as a composite measure for $\mathrm{ftf}$ interaction $(\alpha=0.82)$, and thus they were combined and logtransformed.

Loneliness. Loneliness was measured with the UCLA Loneliness Scale (version 3). ${ }^{35}$ The scores on this scale are stable over time within individuals, ${ }^{33,35}$ thus scholars tend to use this scale to measure a stable tendency of feeling lonely. ${ }^{34,36}$ This scale includes 20 questions such as, "How often do you feel that you are 'in tune' with the people around you?" and "How often do you feel that there is no one you can turn to?" The response format was a 6-point Likert-type scale ranging from 1 ("never") to 6 ("always"), and the responses were recoded and combined so that higher scores indicate greater feelings of loneliness $(M=2.60, S D=0.77, \alpha=0.94)$.

\section{Data analysis}

Preliminary analyses revealed that sex and age had significant effects on a few variables: female students tended to have higher levels of inclusion motive for calling (for males, $M=4.18, \quad S D=1.32$; for females, $M=4.66, \quad S D=1.45$; $t=-2.26, d f=228, p=0.025)$ and escape motive for calling (for males, $M=3.65, S D=1.47$; for females, $M=4.18$, $S D=1.58 ; t=-2.22, d f=228, p=0.027)$ than male students. Also, age was negatively correlated with the frequency of texting $(r=-0.23, n=217, p=0.001)$, pleasure motive for calling $(r=-0.14, n=231, p=0.028)$, and the composite variable of $\mathrm{ftf}$ interaction time $(r=-0.18, n=227, p=0.005)$. Therefore, sex and age were controlled for in the following analyses.

In order to test the proposed path model, structural equation modeling analyses were conducted using Mplus. ${ }^{37}$ Frequency of calling and texting was separately entered into the model as an indicator of cell-phone use (see Figure 2). The average scores of the six motives for calling and texting respectively were put into the model. Additional factor analyses of the six motive scores for each channel confirmed this solution. The factor analyses yielded one factor, explaining $65.9 \%$ of the variance for the calling motive and $75.8 \%$ for the texting motive. Thus the just-identified model, as the proposed model (Figure 1) indicated, was fitted to the partial correlation matrix of the observed variables with sex and age held constant (Table 1). The results of this analysis are reported below.

\section{Results}

The research questions inquired to what extent participants had interpersonal motives for using voice calls and text messaging. Table 2 shows the means and standard deviations of motive scores for using both channels and paired $t$-test results. For calling (RQ1), affection, inclusion, and escape were relatively strong motives, while control, pleasure, and relaxation were relatively weak compared to the others. Similarly, affection, escape, and inclusion were relatively stronger motives for texting (RQ2), while control and relaxation were relatively weaker than the others. Interestingly, interpersonal motives for texting were stronger than for calling in general. A series of paired $t$ tests revealed that four motive scores for texting were significantly higher than those for calling, and this was the case for the averaged score of the six motives as well.

The hypotheses were tested by path analysis presented in Figure 1. H1 posited that increases in interpersonal motives for calling and texting are associated with increases in the

\begin{tabular}{|c|c|c|c|c|}
\hline & Frequency & $\begin{array}{l}\text { Average } \\
\text { motive }\end{array}$ & $\begin{array}{c}\text { Ftf } \\
\text { interaction }\end{array}$ & Loneliness \\
\hline requency & - & $0.42^{* * *}$ & $0.15^{*}$ & $-0.16^{*}$ \\
\hline Average motive & $0.38^{* * *}$ & - & $0.17^{*}$ & -0.11 \\
\hline tf interaction & $0.25^{* * *}$ & $0.20^{* *}$ & - & $-0.27^{* * *}$ \\
\hline oneliness & $-0.19^{* *}$ & $-0.18^{* *}$ & $-0.30^{* * *}$ & - \\
\hline
\end{tabular}

Note: Sex and age were controlled for.

Partial correlations for voice calls are below diagonal $(n=224)$; for text messaging are above diagonal $(n=211)$.

Two-tailed, listwise exclusion of missing data.

${ }^{*} p<0.05 ;{ }^{* *} p<0.01 ;{ }^{* * *} p<0.001$. 
Table 2. Interpersonal Motives for Calling AND TEXTING

\begin{tabular}{lcccccccc}
\hline & \multicolumn{2}{c}{ Calling } & & \multicolumn{2}{c}{ Texting } & & \\
\cline { 2 - 3 } & Mean & $S D$ & & Mean & SD & df & $\mathrm{t}$ \\
\hline Affection & 4.56 & 1.24 & & 4.74 & 1.43 & 218 & $-2.67^{* *}$ \\
Inclusion & 4.54 & 1.44 & & 4.39 & 1.68 & 218 & 1.81 \\
Control & 3.73 & 1.42 & & 3.99 & 1.72 & 218 & $-3.26^{* *}$ \\
Pleasure & 3.70 & 1.46 & & 4.17 & 1.66 & 218 & $-6.69^{* * *}$ \\
Escape & 4.06 & 1.56 & & 4.50 & 1.73 & 218 & $-5.10^{* * *}$ \\
Relaxation & 3.68 & 1.59 & & 3.72 & 1.84 & 218 & -0.51 \\
Average motive $^{\mathrm{a}}$ & 4.03 & 1.20 & & 4.27 & 1.43 & 218 & $-3.93^{* * *}$ \\
\hline
\end{tabular}

${ }^{\mathrm{a}}$ The mean score of the six interpersonal motives.

${ }^{* *} p<0.01 ;{ }^{* * *} p<0.001$.

amount of (a) calling and (b) texting. Indeed, the interpersonal motives for calling and texting were a positive predictor of the frequency of calling $(\beta=0.33, p<0.001)$ and texting $(\beta=0.40, p<0.001)$ respectively. Thus $\mathrm{H} 1 \mathrm{a}$ and $\mathrm{H} 1 \mathrm{~b}$ were supported, implying that the higher the interpersonal motives for using cell phones, the more frequent the cell-phone use.

The second set of hypotheses pertained to the positive link between $\mathrm{ftf}$ interaction and cell-phone use. The path analysis revealed that $\mathrm{ftf}$ interaction significantly predicted calling frequency $(\beta=0.16, p=0.012)$ but not texting frequency $(\beta=0.05, p=0.412)$. Thus $\mathrm{H} 2 \mathrm{a}$ was supported, whereas $\mathrm{H} 2 \mathrm{~b}$ was not. The amount of time people spend with other people in person seems directly related to how frequently they use voice calls but not to how frequently they use text messaging. $\mathrm{H} 3 \mathrm{a}$ and $\mathrm{H} 3 \mathrm{~b}$ were also about $\mathrm{ftf}$ interaction. They posited the positive path coefficients from $\mathrm{ftf}$ interaction to interpersonal motives. The $\mathrm{ftf}$ interaction was a significant predictor for calling motives $(\beta=0.16, p=0.022)$, as well as for texting motives $(\beta=0.15, p=0.027)$, thus supporting $\mathrm{H} 3 \mathrm{a}$ and $\mathrm{H} 3 \mathrm{~b}$. That is, increased daily $\mathrm{ftf}$ interaction is related to increased interpersonal motives for using cell phones.

Loneliness was expected to be negatively related to cellphone use, both for calling (H4a) and for texting (H4b). This was not supported. The path coefficients from loneliness to calling frequency $(\beta=-0.09, p=0.185)$ and to texting frequency $(\beta=-0.10, p=0.110)$ were not significant. The last set of hypotheses concerns the relationship between loneliness and interpersonal motives for cell-phone use. H5a predicted a negative path from loneliness to calling motives, and $\mathrm{H} 5 \mathrm{~b}$ to texting motives. Path analyses confirmed $\mathrm{H} 5 \mathrm{a} \quad(\beta=0.14$, $p=0.043)$ but disconfirmed H5b $(\beta=0.05, p=0.412)$.

Because of the non-significant paths, the path model was reanalyzed with those paths taken out. Figure 2 provides the final models with standardized path coefficients. The model fit indices (the model $\chi^{2}$, CFI, TLI, RMSEA, and SRMR) suggest that the models represent the data reasonably well, although RMSEA barely missed significance. In addition, although the hypotheses mainly tested the direct effects of variables, our path model indicates that interpersonal motives mediate the effects of loneliness and $\mathrm{ftf}$ interaction on
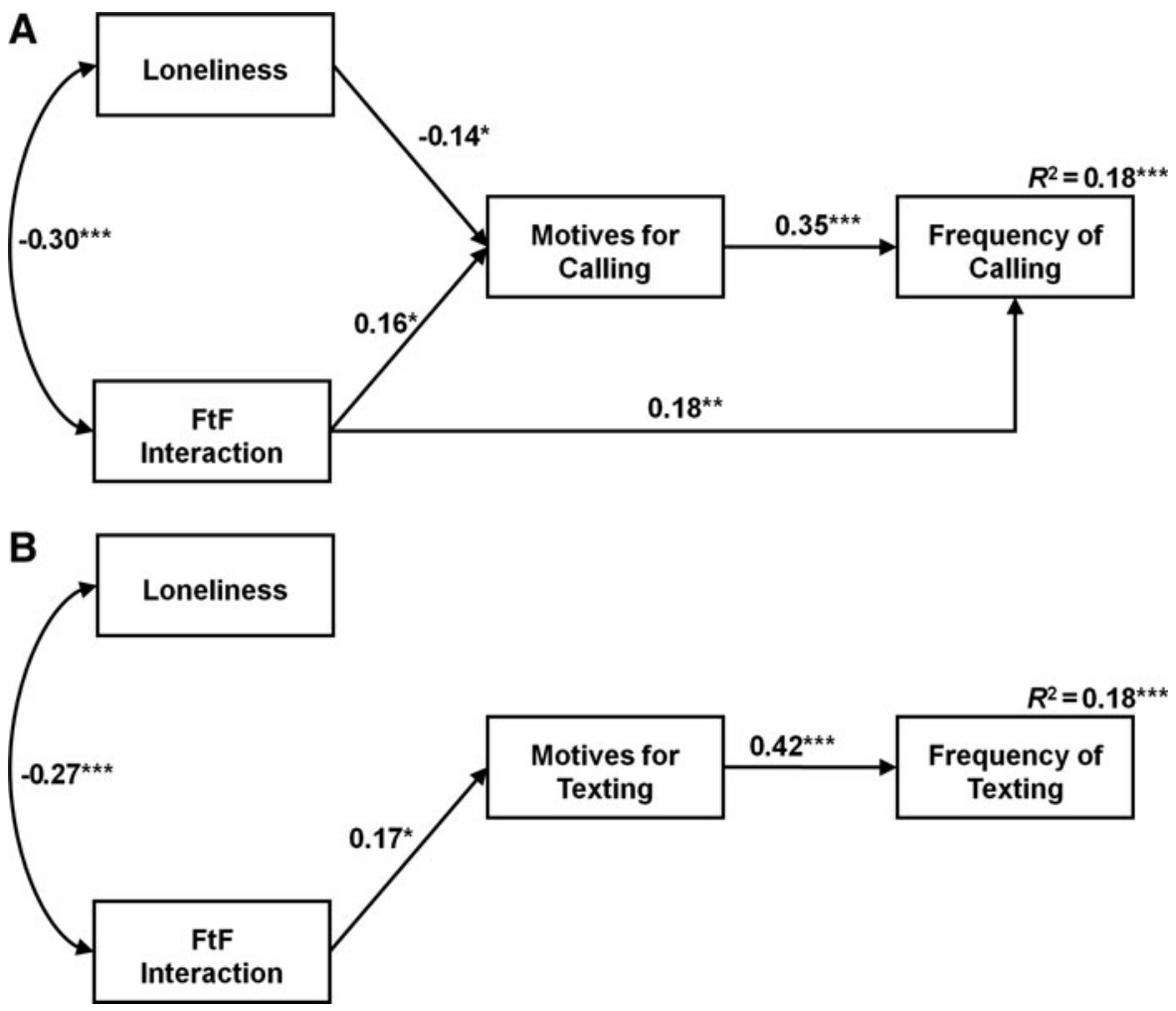

FIG. 2. Final path models. Standardized coefficients are presented. Sex and age were controlled for. Fit indices for model A: $\chi^{2}=1.74, d f=1, p=0.187, N=224, \mathrm{CFI}=0.986, \mathrm{TLI}=0.930$, RMSEA $=0.058(90 \% \mathrm{CI}=0.0 \sim 0.198), \mathrm{SRMR}=0.024$. Fit indices for model B: $\chi^{2}=5.07, d f=3, p=0.167, N=211, \mathrm{CFI}=0.967, \mathrm{TLI}=0.933, \mathrm{RMSEA}=0.057(90 \% \mathrm{CI}=0.0 \sim 0.141), \mathrm{SRMR}=$ 0.055. ${ }^{*} p<0.05 ;{ }^{* *} p<0.01 ;{ }^{* * *} p<0.001$. 
cell-phone use. Therefore, we additionally tested the indirect effects of loneliness and $\mathrm{ftf}$ interaction on cell-phone use. As for voice calls, the indirect effect of loneliness, via motives for calling, on calling frequency was marginal $(\beta=-0.05$, $p=0.057)$, but $\mathrm{ftf}$ interaction had a significant indirect effect, via motives for calling, on calling frequency $(\beta=0.05$, $p=0.033$ ). Regarding text messaging, interpersonal motives significantly mediated the effect of $\mathrm{ftf}$ interaction on frequency $(\beta=0.07, p=0.016)$. These results suggest that $\mathrm{ftf}$ interaction influences cell-phone use not only directly but also by increasing interpersonal motives, which is a strong predictor of cell-phone use.

\section{Discussion}

This study examined college students' cell-phone use and its associations with interpersonal motives for using cell phones, $\mathrm{ftf}$ communication, and loneliness. We emphasize the interpersonal motives for using cell phones, in that enabling communication between people apart is the primary function of the cell phone. Therefore, we assumed that why people communicate on the move would not be different from why people communicate in general. Six interpersonal motives established by Rubin et al. ${ }^{19}$ were investigated in relation to the use of voice calls and text messaging via cell phones. Among those motives, affection, inclusion, and escape were relatively stronger motives than the others for both calling and texting, which suggests that people communicate through cell phones to exchange feelings of caring and connection. This is consistent with what Rubin et al. found. In their study, affection, inclusion, and pleasure were relatively strong motivations compared with the others (i.e., escape, relaxation, and control). Pleasure was also a relatively strong motivation for texting in the present study. These results support our assumption that mobile communication satisfies interpersonal needs, just as ftf communication does. However, differences also emerged. Compared to the original work, ${ }^{19}$ escape was one of the major motivations for cellphone use. That is, participants appeared to enjoy calling and texting as a means of escape from something distressful. Considering that escape is one of the media-use related motives, people may also seek some types of enjoyment by using cell phones in addition to basic interpersonal needs. Interestingly, interpersonal motives for texting were generally stronger than for calling. This result implies more intimate characteristics of texting, particularly for young people, which is consistent with previous findings. 6,38

We proposed a path model to investigate overall relationships among cell-phone use and its interpersonal motives, $\mathrm{ftf}$ interaction, and loneliness. According to the path analysis, interpersonal motives for cell-phone use were significantly connected to the amount of cell-phone use: the stronger the motives, the more frequent the use of voice calls and text messaging. The interpersonal motives turned out to be the best predictor of the amount of cell-phone use in this study. The extent to which people want to communicate with other people is more strongly linked to their usage of cell phones than their in-person contact or loneliness.

Our path model indicates that the interpersonal motives for using cell phones may arise partly from the $\mathrm{ftf}$ communication people conduct every day. The interpersonal motives for calling and texting were significantly related to the amount of $\mathrm{ftf}$ interaction. Mobile communication tends to occur within a close social network in which people know each other well and see each other often in person. ${ }^{20,22}$ These frequent close contacts may lead people to want to or need to connect when they are not physically together, and cell phones seem to serve well the needs to connect. However, $\mathrm{ftf}$ interaction was not significantly associated with the frequency of text messaging, while it was with the frequency of voice calls, which implies that $\mathrm{ftf}$ communication has a stronger association with using voice calls than with text messaging. This finding is somewhat surprising in that previous studies found texting is closely related to one's close interpersonal relationships. ${ }^{38}$ Possibly, the quality of $\mathrm{ftf}$ communication with other people, rather than the amount of $\mathrm{ftf}$ communication, matters for individuals' text messaging. Because texting is relatively informal and intimate, as compared with calling, increases in the amount of $\mathrm{ftf}$ contact with other people may not directly increase the amount of texting with them. It would be an interesting future study to examine what factors of $\mathrm{ftf}$ communication or relationship are related to calling and texting respectively. The amount of $\mathrm{ftf}$ interaction, however, affected both calling and texting through the medium of interpersonal motives.

Previous studies on loneliness have consistently found that lonely people tend to avoid interpersonal interaction and are somewhat socially incompetent. ${ }^{31,33}$ Accordingly, this study found a significant negative association between loneliness and $\mathrm{ftf}$ interaction, although this was not hypothesized. The lonelier the participants, the less they were involved in $\mathrm{ftf}$ communication with family, friends, and coworkers. However, loneliness was not directly related to the use of voice calls or text messaging. Taken together, loneliness appeared to affect cell-phone use only by way of influencing $\mathrm{ftf}$ interaction. That is, the feeling of loneliness established for certain reasons, such as a failure to relate to other people effective$\mathrm{ly}_{,}{ }^{28}$ may discourage the lonely from getting involved in $\mathrm{ftf}$ interaction with others, which may in turn prevent them from communicating through cell phones.

Also, interpersonal motives for cell-phone use were not associated as strongly as expected with loneliness. Although loneliness was a negative predictor of calling motives, it was not a significant predictor of texting motives. Lonely people seem to be less motivated to use cell phones, particularly voice calls, than non-lonely people. These results corroborate the previous findings on loneliness and interpersonal outcomes $^{31,39}$ in the context of mobile communication. That is, consistent with in $\mathrm{ftf}$ settings, lonely people may find mobile communication less or at least no more affectionate and pleasant than people who are not lonely, and thus they are less likely to engage in it with interpersonal reasons.

\section{Conclusion}

To conclude, our findings indicate that individuals' cellphone use is strongly associated with how much they are motivated by interpersonal purposes, such as feeling affection and inclusion. These motives were significantly related to the amount of everyday in-person contact a person experiences, which is closely associated with loneliness. Although $\mathrm{ftf}$ communication may not strongly influence mobile communication itself, it has effects on mobile communication by influencing the extent to which people want to use cell phones for interpersonal purposes. 
The limitations of the present study include the self-report method employed to measure the quantity of mobile communication. Since participants had to recall and estimate the frequency of using cell phones, employing various measurements such as keeping diaries would ensure more valid data. In addition, frequency of cell-phone use may not represent the quantity of cell-phone use very well because assessing the time of cell-phone use may yield different results, particularly for voice calls. In terms of the quantity of communication, $\mathrm{ftf}$ interaction focused on the time spent with other people only. There must be plenty of ways to assess an individual's characteristics in relation to his or her interpersonal communication. In future studies, assessing a more diverse and broader range of communication aspects regarding both $\mathrm{ftf}$ and mobile communications would produce more valid and reliable results.

Although it seems quite plausible that loneliness and $\mathrm{ftf}$ interaction affect mobile communication, we cannot exclude the possibility of the other direction of causality. For instance, being unable to use cell phones may temporarily lead people to have fewer $\mathrm{ftf}$ contacts. Considering that people can coordinate their in-person meeting schedules through cell phones, ${ }^{38}$ the lower levels of $\mathrm{ftf}$ and mobile communications may contribute to their feelings of loneliness. This limitation can be addressed by employing stricter methodological controls such as panel studies in order to establish the direction of causality between loneliness, $\mathrm{ftf}$ interaction, and cell-phone use. In addition, data from a more representative sample in terms of age and gender would substantiate our findings.

Despite these limitations, this study contributes to our knowledge on the nature of mobile communication in the context of interpersonal communication. These findings highlight that cell-phone use is closely associated with how well mobile communication satisfies the interpersonal motives, and that these motives are, in turn, associated with daily $\mathrm{ftf}$ interaction and loneliness.

\section{Disclosure Statement}

No competing financial interests exist.

\section{References}

1. Student Affairs Administrators in Higher Education. (2008) Profile of today's college student. http://www.naspa.org/ 2008\%20technology\%20use.pdf (accessed Sep. 30, 2009).

2. Ramirez A Jr, Dimmick J, Feaster J, et al. Revisiting interpersonal media competition: The gratification niches of instant messaging, e-mail, and the telephone. Communication Research 2008; 35:529-47.

3. Maslow AH. (1968) Toward a psychology of being. New York: Van Nostrand.

4. Schutz WC. (1966) The interpersonal underworld. Palo Alto, CA: Science and Behavior Books.

5. Baumeister RF, Leary MR. The need to belong: Desire for interpersonal attachments as a fundamental human motivation. Psychological Bulletin 1995; 117:497-529.

6. Licoppe C. "Connected" presence: The emergence of a new repertoire for managing social relationships in a changing communication technoscape. Environment \& Planning D: Society \& Space 2004; 22:135-56.

7. Katz JE, Aakhus M, eds. (2002) Perpetual contact: Mobile communication, private talk, public performance. Cambridge, England: Cambridge University Press.
8. Leung L, Wei R. More than just talk on the move: Uses and gratifications of the cellular phone. Journalism \& Mass Communication Quarterly 2000; 77:308-20.

9. Wei R, Lo V-H. Staying connected while on the move: Mobile phone use and social connectedness. New Media \& Society 2006; 8:53-72.

10. Ishii K. Implications of mobility: The uses of personal communication media in everyday life. Journal of Communication 2006; 56:346-65.

11. Sloan WW, Solano $\mathrm{CH}$. The conversational styles of lonely males with strangers and roommates. Personality \& Social Psychology Bulletin 1984; 10:293-301.

12. Solano CH, Batten PG, Parish EA. Loneliness and patterns of self-disclosure. Journal of Personality \& Social Psychology 1982; 43:524-31.

13. Davis RA, Flett GL, Besser A. Validation of a new scale for measuring problematic Internet use: Implications for preemployment screening. CyberPsychology \& Behavior 2002; 5:331-45.

14. Rubin AM, Perse EM, Powell RA. Loneliness, parasocial interaction, and local television news viewing. Human Communication Research 1985; 12:155-80.

15. Dimmick JW, Sikand J, Patterson SJ. The gratifications of the household telephone: Sociability, instrumentality, and reassurance. Communication Research 1994; 21:643-64.

16. O'Keefe GJ, Sulanowski BK. More than just talk: Uses, gratifications, and the telephone. Journalism \& Mass Communication Quarterly 1995; 72:922-33.

17. Singer BD. (1981) Social functions of the telephone. Palo Alto, CA: R\&E Research Associates.

18. Auter PJ. Portable social groups: Willingness to communicate, interpersonal communication gratifications, and cell phone use among young adults. International Journal of Mobile Communications 2007; 5:139-56.

19. Rubin AM, Perse EM, Barbato CA. Conceptualization and measurement of interpersonal communication motives. Human Communication Research 1988; 14:602-28.

20. Campbell SW, Russo TC. The social construction of mobile technology: An application of the social influence model to perceptions and uses of mobile phones within personal communication networks. Communication Monographs 2003; 70:317-34.

21. Jin B, Peña J. Mobile communication in romantic relationships: Mobile phone use, relational uncertainty, love, commitment, and attachment styles. Communication Reports 2010; in press.

22. Kim H, Kim GJ, Park HW, et al. Configurations of relationships in different media: Ftf, email, instant messenger, mobile phone, and SMS. Journal of Computer-Mediated Communication 2007; 12:1183-207.

23. Campbell SW, Kelley, MJ. Mobile phone use in AA networks: An exploratory study. Journal of Applied Communication Research 2006; 34:191-208.

24. Jin B. (2007) Mobile communication as a mode of interpersonal communication. Paper presented at the National Communication Association Convention, Chicago.

25. Reid DJ, Reid FJM. Text or talk? Social anxiety, loneliness, and divergent preferences for cell phone use. CyberPsychology \& Behavior 2007; 10:424-35.

26. Leary MR. Social anxiousness: The construct and its measurement. Journal of Personality Assessment 1983; 47:66-75.

27. Cacioppo JT, Hawkley LC, Berntson GG. The anatomy of loneliness. Current Directions in Psychological Science 2003; 12:71-4. 
28. Jones W. (1982). Loneliness and social behavior. In Peplau LA, Perlman D, eds. Loneliness: A sourcebook of current theory, research and therapy. New York: Wiley-Interscience, pp. 283-52.

29. Peplau LA, Russell D, Heim M. (1979) The experience of loneliness. In Frieze I, Bar-Tal D, Carroll JS, eds. New approaches to social problems: Applications of attribution theory. San Francisco: Jossey-Bass, pp. 53-78.

30. Perlman D, Peplau LA. (1981) Toward a social psychology of loneliness. In Duck S, Gilmour R, eds. Personal relationships 3: Personal relationships in disorder. New York: Academic Press, pp. 31-56.

31. Spitzberg BH, Canary DJ. Loneliness and relationally competent communication. Journal of Social \& Personal Relationships 1985; 2:387-402.

32. Cheek JM, Busch CM. Influence of shyness on loneliness in a new situation. Personality \& Social Psychology Bulletin 1981; 7:573-77.

33. Russell DW, Peplau LA, Cutrona CE. The revised UCLA Loneliness Scale: Concurrent and discriminant validity evidence. Journal of Personality \& Social Psychology 1980; 39:472-80.

34. Finn S, Gorr MB. Social isolation and social support as correlates of television viewing motivations. Communication Research 1988; 15:135-58.
35. Russell DW. UCLA Loneliness Scale (version 3): Reliability, validity, and factor structure. Journal of Personality Assessment 1996; 66:20-40.

36. Morahan-Martin J, Schumacher P. Loneliness and social uses of the Internet. Computers in Human Behavior 2003; 19:659-71.

37. Muthén LK, Muthén BO. (2007) Mplus user's guide. 5th ed. Los Angeles: Muthén \& Muthén.

38. Ling R, Yttri B. (2002) Hyper-coordination via mobile phones in Norway. In Katz JE, Aakhus M, eds. Perpetual contact: Mobile communication, private talk, public performance. Cambridge, England: Cambridge University Press, pp. 139-69.

39. Hosman LA. The relationships among need for privacy, loneliness, conversational sensitivity, and interpersonal communication motives. Communication Reports 1991; 4:73-80.

Address correspondence to: Borae Jin

Department of Communication Studies University of Texas at Austin 1 University Station A1105 Austin, TX 78712-0115

E-mail: bjin@mail.utexas.edu 